\title{
Radial Artery
}

National Cancer Institute

\section{Source}

National Cancer Institute. Radial Artery. NCI Thesaurus. Code C12838.

The branch of the brachial artery that passes down the forearm. 